\title{
SOCIAL INNOVATIONS IN GEO-ICT EDUCATION AT TANZANIAN UNIVERSITIES FOR IMPROVED EMPLOYABILITY (GeoICT4e)
}

\author{
N. Käyhkö ${ }^{a^{*}}$, M. Mbise ${ }^{\mathrm{b}}$, Z. Ngereja ${ }^{\mathrm{c}}$, M.O. Makame ${ }^{\mathrm{d}}$, E. Mauya ${ }^{\mathrm{e}}$, G. Matto ${ }^{\mathrm{f}}$ E. Timonen-Kalliog ${ }^{\mathrm{g}}$, R. Rancken ${ }^{\mathrm{h}}$ \\ a* Department of Geography and Geology, University of Turku (UTU), Finland, niina.kayhko@utu.fi \\ ${ }^{\mathrm{b}}$ College of ICT, University of Dar es Salaam (UDSM), Tanzania, Mercy Mbise, mercymbise@ gmail.com \\ ${ }^{c}$ Department of Geospatial Sciences and Technology, Ardhi University (ARU), Tanzania, ngereja@ gmail.com \\ ${ }^{\mathrm{d}}$ Department of Social Sciences, State University of Zanzibar (SUZA), Tanzania, maqam04@ gmail.com \\ ${ }^{\mathrm{e}}$ Department of Forest Engineering and Wood Science, Sokoine University of Agriculture (SUA), Tanzania, \\ ernestmauya@gmail.com \\ ${ }^{\mathrm{f}}$ ICT Department, Moshi Co-Operative University, Tanzania, gmatto2004@yahoo.co.uk \\ ${ }^{\mathrm{g}}$ Faculty of Health and Well-being, Turku University of Applied Sciences, Finland, eeva.timonen-kallio@turkuamk.fi \\ ${ }^{\mathrm{h}}$ Department of Bioeconomy, Novia University of Applied Sciences, Finland, romi.rancken@ @ovia.fi
}

KEY WORDS: Geospatial technologies, Open Data, Challenge-based learning, Multi-Competence Learning, MOOCs, Social Innovations, Curricula development, Learning Services

\begin{abstract}
:
Geospatial and ICT technologies are making an impact leap due to globally accessible open data solutions addressing environmental and social challenges, such as rapid urbanization, degradation of marine and land environments, and humanitarian crises. We are witnessing a rapid growth of innovations built on data and tools tackling local societal problems. At best, these can provide better opportunities for sustainable solutions and development. The need for geospatial expertise is growing globally, and the required skills and capabilities of experts are changing. Universities need to think that although the future jobs rely on experts' geospatial data and technology skills, graduates need to have a strong conceptual and practical understanding of societal problems and capacity to co-develop solutions, which generate wellbeing and inclusive development. New generation university graduates need to master the interface between technologies' potential and societies' emerging needs, working in a multi-stakeholder environment and creating innovative and impactful solutions. In this paper, we present a model of institutional cooperation between five Tanzanian and three Finnish universities, aiming to tackle this transformative education challenge in Tanzania. GeoICT4e aims to develop innovative and scalable geospatial and ICT e-learning services for Tanzanian universities. Via this transformation, universities are aiming to enhance the future employment potential of the graduates with digital multi-competence skills. We present the overall methodology and key activities of the project cooperation, and discuss the opportunities and challenges related to this transformation, and use of open data and FOSS solutions particularly from the institutional and societal perspectives.
\end{abstract}

\section{INTRODUCTION}

\subsection{From technological to social innovations}

Geospatial data and ICT technologies have made a major global accessibility and impact leap over the last years, leading to promising technological innovations all over the world. Global data repositories and platforms such as Open Street Map, Google Earth Engine, Earth Explorer, and ESA Sentinel data hub have enabled online and open access to vast amounts of spatial data without major local investments to physical data infrastructures. Geospatial data, technology and application markets are booming and these developments are speeded up with more accessible digital data processing environments, with integrated machine learning and artificial intelligence algorithms, as well as automation and IoT solutions (Madhavan, 2018, Sullivan et al., 2018, GeoBuiz, 2019). As a result, we are currently witnessing rapid growth of digital data collection, mapping and monitoring solutions built on open geospatial data, affordable mobile technologies and earth observation data and methods.

Rapidly developing countries have a vast amount of environmental and social problems, especially when looking at them through the lenses of sustainable development. These real world needs are contextual and dynamic in space and time and call for novel data and technology solutions. We have already seen several examples of how these opportunities can be turned into local solutions that are able to address major planetary challenges, such as rapid urbanization, degradation of marine and land environments and humanitarian crises caused by natural disasters such as earthquakes and floods (Goodchild and Glennon, 2010, Avle et al., 2018, Petersson et al., 2020). Drones (UAVs) have diversified and made mapping and monitoring opportunities cheaper, efficient and accessible (Tiwari and Dixit, 2015). Participatory data collection and citizen science initiatives have transformed the ways digital data and services can be built in previously data-scarce environments for improved sustainability (Bakker and Ritts, 2018, Fritz et al., 2019). These are just a few examples of the prominent directions. Despite these positive developments, there are major concerns if digital innovations built on new technologies and globally accessible data are able to bring inclusive and sustainable development opportunities for the people and the communities locally.

It is important to ensure that the digital divide, which we have witnessed distinctively during the COVID-19 outbreak, is diminished by actions at multiple levels from policy to 
institutions, to education and research and workforce actions (Young et al., 2020, UNCTAD, 2021). During the digital era, we should not be content with data and technology advancement only, but thrive for turning these resources into social innovations, which catalyse growth and increase the wellbeing of the people and the planet. At best, sustainable innovations happen in a dynamically evolving interface between technologies' potential and societies' emerging needs. Solutions, which are contextually clever, adaptive and driven by local talent and strong linkages to local innovation ecosystem, are much needed. Putting local social, cultural, economic and environmental impacts in the frontline is a service for the sustainable and secure future of the data and technology achievements.

\subsection{Need for transformative change in learning and competence development}

The opportunity space of social innovations calls for transformation in the ways future geospatial and ICT experts are educated and how their professional skills and competences are built while they are studying and getting prepared for the work life. New generation students and graduates need strong geospatial data and tool competences, but they also need to understand societies' emerging needs and sustainability challenges in a contextually clever and forward-looking way. Increasingly it is not only how technology savvy students are, but how do we strengthen their intellectual understanding of the complex real-word problems and their capacity and cleverness to cooperate and link with different type of people and knowledge requirements. Thus, students need coaching into proactive and participatory ways of working together with the problem-owners in the society in order to turn universal tools and open data into locally relevant and impactful solutions.

Such learning conditions will not happen in conventional classroom teaching or learner-instructor set-ups, but rather in such environments, where teams of students with different skills work with real world challenges and are able to co-create new ideas and solutions (Martin and Bollinger, 2018, Portuguez Castro and Gómez Zermeño, 2020, Rådberg et al., 2020). If students obtain relevant skills and professional confidence during their studies, they become stronger future solution providers for an increasing amount of multidimensional problems in society. Students' proactive role in the society will simultaneously trigger new job prospects in rapidly changing labor markets, and thus improve graduates' future employment opportunities. Creating pedagogical learning services enabling the above-mentioned conditions is not a straightforward task, since universities teaching and learning practices are adaptations to prevailing culture and norms, and institutions' practices usually chance slowly over time. There is often also a gap between what is anticipated and desired learning goals and methods, and how things are practically implemented in learning environments with shortage of resources.

However, working with institutional development of learning services is a crucial component of successful transformation since without system-level and long-term established changes in the actual teaching and learning practices, advancements become only triggered by random opportunities or projects with limited time and impacts. Universities learning materials and activities need to support students' skills growth from conceptual understanding to real practical solution solver skills, and enable learning flexibly anytime and anywhere. The digital divide is a reality between universities, but the opportunity space in rapidly developing countries is prominent, since students are highly motivated to make positive impacts to their own society and learn societally relevant skills, and data and technology opportunities are much more accessible and inclusive today. While COVID-19 has challenged learning service developments over the last year and a half, it has also created an additional layer of institutional motivation and speed for digital learning service developments and changes.

\subsection{Geospatial and ICT learning and skills development needs in Tanzanian universities}

In Tanzania, geospatial-ICT education has taken giant steps during the last years in terms of new degree programmes, growth of basic geospatial data and technology skills of staff and students and new infrastructures and tools (Käyhkö et al 2018a). This has been a result of multiple co-existing initiatives and developments in geospatial and ITC education, research and capacity building activities between Tanzanian universities and their many international partners. Various government, private sector and NGO initiatives and several donor-funded projects have also triggered needs for new digital geospatial data and technology solutions. These have recently expanded geospatial expertise demand outside traditional geoinformation and surveying domains. As couple of recent examples, Tanzania President's Office-Regional Administration and Local Government is currently implementing a program to mainstream GIS in twenty Local Government Authorities. Integrated Urban Development Project (BIG-Z) on the other hand aims at improving living conditions and promote local economic development in Zanzibar largely with the support of digital geospatial data and technologies (see: http://bigzanzibar.org/).

Despite positive changes, universities' education has several development challenges amidst these digitalization and growth opportunities. Firstly, teaching focuses still too much on increased enrolment without considering new strategies for delivery of practical skills learning to a large number of students inside and outside universities. Secondly, staff's skills and capacities have improved but teachers need support to transform their skills to pedagogically high-quality e-learning materials and diverse learning solutions for their students also outside classrooms and in innovative set-ups. Thirdly, students are gradually stronger with basic level geospatial and ICT skills, but they have limited opportunities to widen and apply these skills during their studies and be challenged to create new solutions for new needs in the society. Deeper learning, and adoption of entrepreneurial mind-set does not happen unless students get exposed to learning in multi-disciplinary cross-program setups, solving real-world challenges. Furthermore, multi-domain skills learning requires access to digital geospatial data. Students' access to reliable digital data, cloud platforms for data processing and e-learning resources in general needs to be improved as part of the universities' study programmes and courses.

Altogether, lack of applied skills and contextual understanding of the society's needs and sustainability dimensions increases a risk that universities' supply of graduates is unable to respond to increasingly diversifying digital solution demands in the society. This again increases the risk that digital jobs related to geospatial skills are taken by foreign experts, rather than become populated with local talents. Universities alone, 
however, have limited influence on digital markets and thus much more cooperation is needed with innovation actors to cocreate transformative change and the future labour demand. In this paper, we present an overall methodology and key activities of an institutional geospatial and ICT education development project "GeoICT4e" (2020-2024), which expands the well-established long-term institutional cooperation of the University of Turku (UTU, Finland) with Tanzanian universities since early 2000 (Käyhkö et al., 2018a). GeoICT4e focuses on improving management and teaching capacities of Tanzanian universities in socially innovative geospatial and ICT education by improving both staff competence and students learning opportunities, as well as creating open and widely access to e-learning assets and co-creation spaces for the students for their improved multi-domain skills development and better future employment opportunities.

\section{GEOICT4E AS AN INSTITUTIONAL EDUCATION COOPERATION PROJECT}

\subsection{Institutional partners and the cooperation space}

GeoICT4e is grounded on long-term and well-established institutional cooperation between the University of Turku (UTU, Finland) and Tanzanian universities. UTU has led altogether nearly 20 research, education and development cooperation projects in cooperation with various local institutions in Tanzania. These projects have addressed development potential of geospatial data and technologies in various application fields, such as land changes, land use/land cover mapping, ecosystem services, land use and coastal planning and innovations (see: https://tanzania.utu.fi/). Codeveloping institutional geospatial and ICT capacities has been in the core of the UTU's cooperation with the Tanzanian universities. With the support of the HEI-ICI funding scheme of the Government of Finland, UTU has coordinated three HEIICI projects since 2013. HEI-ICI (The Higher Education Institutions Institutional Cooperation Instrument) supports subject-specific, methodological, educational and administrative cooperation between higher education institutions in Finland and the developing world, targeting to enhance higher education provision in these countries. (https://www.oph.fi/en/programmes/hei-ici-programme).

First HEI-ICI project was jointly with the University of Dar es Salaam (UDMS) and focused on geospatial capacities (HEIGIS 2013-15). The second one was consortium between UTU and four Tanzanian universities: UDSM, the Ardhi University (ARU), the Sokoine University of Agriculture (SUA) and the State University of Zanzibar (SUZA) (GeoICT 2017-2020, http://geoict.org). The third GeoICT4e (2020-2024) expanded into a eight-university consortium with five Tanzanian and three Finnish universities. The partners are UTU, UDSM, ARU, SUA, SUZA, the Moshi Cooperative University (MoCU), Turku University of Applied Science (TurkuUAS) and Novia University of Applied Science (NoviaUAS). Universities work in cooperation with various innovation ecosystems and societal actors to co-create geospatial and ICT e-learning services for Tanzanian universities. The main objective of the GeoICT4e is that Tanzanian universities have improved management and teaching capacities in socially innovative geospatial and ICT education.

GeoICT4e project's development targets will be reached through three main consortium level actions. Firstly, staff's skills and competences in designing and implementing multi- competence learning (MCL) solutions in their teaching will be improved. Secondly, digital skills and multi-competences of Tanzanian university students will be enhanced. Thirdly, the consortium will improve students' access and wider usage of online digital e-learning assets, such as open data, open tools, e-learning resources and MOOCs. The target in on undergraduate (BA, BSc) and postgraduate level (MSc) programmes and students enrolled in different disciplinary programmes, mainly geospatial sciences (GIS \& RS, geoinformatics, geography, geomatics), Information and communication technology and engineering, and applied fields with strong geospatial application potential (eg. land use planning, environmental sciences, forestry, social sciences, business). The project aims in advancing universities' institutional uptake and management capacities related to the aforementioned qualities, and especially their ability to reach a wider audience and impact with the geospatial and ICT related innovation education.

The GeolCT4e project couples tightly with the ongoing World Bank-funded Tanzania Resilience Academy (RA, https://resilienceacademy.ac.tz/), which is coordinated by UTU, UDSM, ARU, SUA and SUZA. Resilience Academy is a World Bank -led university partnership and service delivery program aiming to improve digital skills, competences and employment of the African youth for more effective disaster risk management. Resilience Academy has been operational in Tanzania since 2018 as a cooperation between the World Bank, the universities and the national and international partners of the Tanzania Urban Resilience Programme (TURP).

\subsection{Co-creative challenge campaigns and multi- competence learning}

The central vehicle for education transformation in GeoICT4e is the students' multicompetence learning (MCL) process, which happens via co-creative challenge campaigns organized in close cooperation with the innovation ecosystem actors and problem owners. This methodology enables universities to catalyse a change, which we identify as 'socially innovative geospatial and ICT education transformation' (Figure 1). The essential elements of the MCL approach, which is grounded on the principles of challenge-based learning (Rådberg et al., 2020), is that students' competences improve simultaneously in multiple knowledge domains.

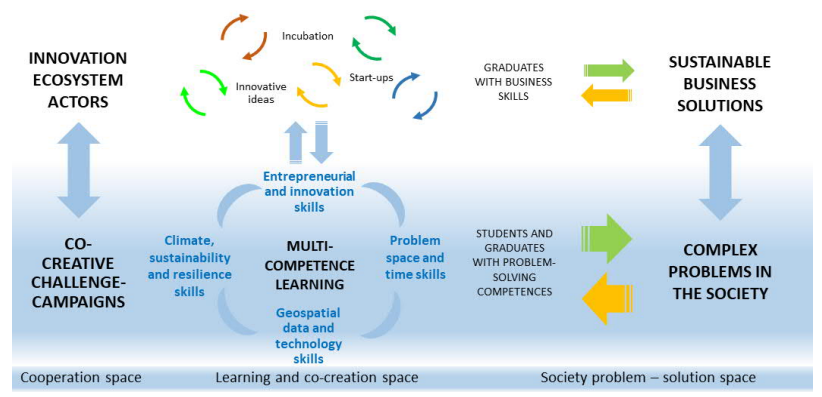

Figure 1. GeoICT4e is aiming for socially innovative geospatial and ICT education transformation, which endorses multi-competence learning (MCL) opportunities of the students. 
Firstly, students are solving real, complex problems of the surrounding society and thus they need to understand the root causes and consequences of the problems and their spatial and temporal dimensions. Secondly, students need to obtain skills in collecting and using digital geospatial data and open-source geospatial and ICT technologies in a novel manner. Digital data is a key asset for problem solutions and mastery of the data and tools with local users is a crucial asset for inclusive design of the solutions. Thirdly, students' abilities and professional confidence evolve in multi-stakeholder teams so that they know how to approach real-word challenges in a contextually clever manner, working for problem-owners towards innovative and influential solutions. Fourthly, global change is creating uncertainty and unpredictability to our socioecological systems. Students need to have skills to design climate-smart and resource-efficient solutions for social, cultural, environmental and economic sustainability and improved resilience.

The MCL process leans on challenge based learning (CBL) principles (Blevis, 2010, Gaskins et al., 2015, Malmqvist et al., 2015, Rådberg et al., 2020), where learning is organized around real-life challenges provided by external partners and carried out in student- and teacher-led multi-disciplinary teams. Students will formulate a concrete actionable challenge based on a broader societal challenge, investigate, research, brainstorm solution concepts and strategies, implement solution prototypes and evaluate them together with real stakeholders in order to provide a pragmatic, progressive learning experience in boosting students' professional development and competences. The essential idea in GeoICT4e is that we link CBL learning to the above-mentioned multicompetence learning themes. The MCL learning takes place through 3-5 months long co-creative challenge campaigns, where students' skills and professional competencies develop in relation to the challenge at hand. The team will organize five challenge campaigns during the course of the project, each led by a local university, and supported by a team of experts from all universities and innovation partners (Figure 2). CBL pedagogy means changing the role of university teachers. They are urged to reflect and co-create learning environments, which inspire students to deconstruct and reformulate actionable challenges, based on a broader societal needs.

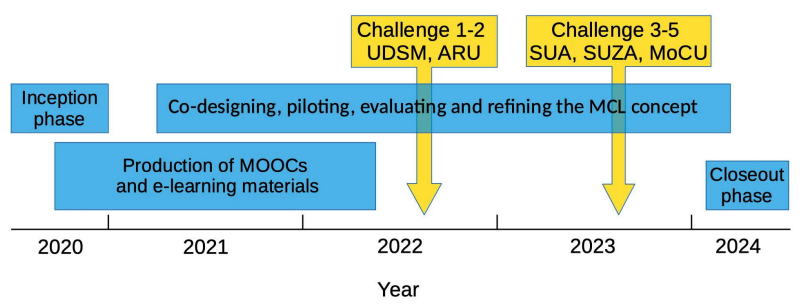

Figure 2. Through co-designed and repetitive CBL campaigns, the MCL methodology develops and is documented into an online MCL Playbook, which contains links to produced elearning resources and practices.

At the end of each co-creation process, the campaign teams organize the co-creation and evaluating workshops with all stakeholders to collect experiences and review the success of campaigns in 'serving of public good' as well as multidisciplinary learning with pedagogical experiments. Repeating CBL campaigns ensures that the overall MCL methodology of the project iterates and develops over time. Students' learning is studied before, during and after the CBL campaigns and personal learning impacts are measured through surveys and interviews of the students and teams. GeoICT4e interfaces tightly with the actors in the local innovation and entrepreneur ecosystem: technology and innovation hubs, living labs, accelerators, data labs and corporate entrepreneurship programs. For each challenge campaign, we seek thematic cooperation from the challenge related experts in the government, NGO and private sector institutions. We will also actively engage the "problem-owners", including the citizens, into our challenge campaigns and put our students to work with them. By linking our CBL campaigns to our existing cooperation with the Tanzania Resilience Academy, we seek to affect the demand market of the experts, although our focus is on improving the quality of the supply of future experts from the universities.

\subsection{Development of open-access e-learning assets}

Our education transformation will accelerate multiple learning opportunities within and outside universities when we make all our learning assets digital and open, and widely accessible for anyone to use. This concerns digital geospatial data, which we will store, share and reuse, and e-learning materials, which we package into nugget-sized mini-MOOCs and self-study packages and serve them free-of-charge for self-studying. The project team aims to publish 40-50 open-access learning material packages during the project. The topics of these elearning materials cover the four key domains of our MCL model. We make these e-learning packages rather compact in size (mini-MOOCs) and endorse the following qualities. Firstly, each learning package takes only one to two days to study. Secondly, each package consists of a combination of small learning entities (nuggets), such as mini-lectures served as videos, quizzes and practical tasks. Thirdly, materials are designed so that they facilitate primarily independent learning. and the packages and their nuggets can thus be flexibly integrated into any local course and context. Finally, materials will be openly available e-learning resources shared via DigiCampus platform (https://digicampus.fi/?lang=en).

We will also utilize globally available open learning materials and MOOCs in combination with these locally made materials. The team will also promote usage of global and regional openaccess geospatial data repositories and platforms to ensure that practical nuggets use real geospatial data sets relevant for the course topic. We aim to gather Tanzania-specific geospatial data sets to an open-access data repository using Geonode to facilitate education and research related learning opportunities of the students with local data sets. These actions will expand our already established digital data services of the Tanzania Resilience Academy (Climate Risk Database, https://geonode.resilienceacademy.ac.tz/). On top of these consortium wide efforts, the project also supports local investments at the universities for e-learning environments. These investments are made at each university based on their local needs.

\subsection{Integrating solutions to local curricula and courses}

Nearly 50 senior and junior level experts from the partner universities implement the project. On top of coordination and management work, experts work in small thematic teams codesigning the activities and ensuring the institutional uptake of 
the e-assets and CBL-MCL pedagogy innovations (Figure 3). The core team related to the institutional uptake are the experts in charge of the CBL-MCL learning methodology development, e-assets and mini-MOOCs and curricula and course developments. For each CBL campaign, there will be multiple innovation and society experts, who are able to provide insights into the challenges from the perspective of the problems' spatial and temporal dimensions and local context, as well as entrepreneurial approach and innovation aspects. Experts also work closely in university-specific teams to develop their localized learning service solutions based on collectively produced e-assets. Teams continue an already earlier initiated development of undergraduate and postgraduate programs and courses towards improved contents and pedagogy (Käyhkö et al. 2018a, Leinonen et al. 2018).

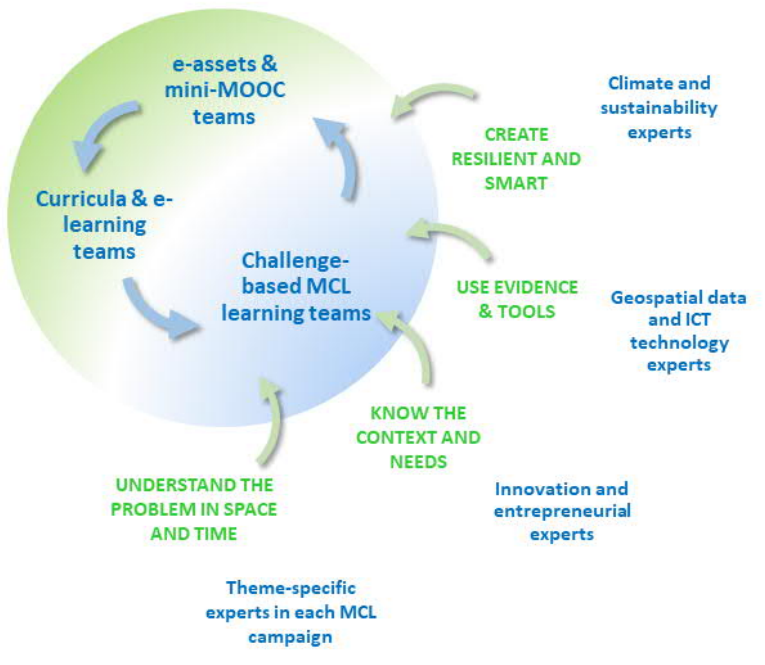

Figure 3. GeoICT4e experts work in thematic teams, which consists of experts from multiple universities and from the innovation ecosystem.

Institutional confidence, co-learning and sharing of good practices is grounded on individual experts knowing each other and being motivated to share their experiences related to institutional opportunities and challenges and piloting new solutions. Furthermore, awareness and marketing of the work to a higher level at each university is an important aspect of the cooperation and institutional acceptance of the work of the team. Thus, GeoICT4e funding is facilitating staff mobility within Tanzania and between Finland and Tanzania, training of the trainers -sessions physically and online, organising cooperation and co-design workshops and participation in education, science, technology and innovation events to share experiences. As institutional competence development is a long-term, evolutionary process, the project is putting specific emphasis on improving management capacities related to the integration of e-learning contents and MCL methodology to local curricula. An important element is developing education cooperation partnerships with societal and particularly innovation actors and developing universities learning environments, such as ICT labs, library and education support capacities for improved access to digital resources.

Use open access software (QGIS, Grass, R, Open Foris etc), open data and affordable ICT technologies is in the heart of the learning solutions. The team is looking into multiple institutional solutions to embed the learning methods and contents innovatively: CBL courses, hackathons, data challenges, innovation co-design events, and supports universities to use e-learning assets (including cloud-based platforms) as integrated components in the local courses. To facilitate the scalability of the multi-competence learning (MCL) approach in geospatial and ICT education results, we summarize and transform our 4-year institutional development process into a Multi Competence Learning (MCL) Playbook, together with the mini-MOOCs. It describes universities' multidisciplinary education strategy and pedagogical e-learning scaffoldings with digital learning assets such as principles of MCL, a guidance how to apply CBL-MCL education at HEIs' teaching, a description of a students' multi-competence profile, instructions how it works together with learning assets (nuggets, mini-MOOCs, cloud platforms, digital data) etc.

\section{CONCLUSIONS}

Institutional development projects' true impacts are discovered usually over a long-time period. The objectives of the GeoICT4e project are ambitious and aim for transformative change, which happens between the universities' learning services and societies' needs for skilled work force and commitments to enhance life qualities with innovative means. Success of this transformation is dependent on many interlinked issues, which are not restricted only to actors and institutions, experts, students and their capacities. Instead, there are many societal factors, which challenge success of innovative education initiatives. By working in close cooperation with innovation ecosystem actors and processes, universities will improve their success potential in making geospatial and ICT education more relevant and influential but this cooperation space contains many assumptions and risks, which may slower anticipated results. One of the key assumptions is related to the overall digitalization and innovation sector development in Africa and in Tanzania in particular. We assume that the trend is positive and that both policy environment as well as investments will flow to Tanzania regarding various industry sectors typically relying on digital data and location technologies.

Location-technology, geospatial data, Earth Observation, ICT and AI solutions are also likely to spread from their traditional application sectors to wider location-intelligence business solutions, as we see globally happening. Geospatial solutions have finally become ubiquitous and integrated into most of the ICT sector system and service solutions (GeoBuiz, 2019). It is vital that when these technologies are turned into local services, locally competent work force is available and is used. There is also an anticipation that the digital job market creates a strong niche for open data and open-source technology solutions, endorsed by local and international institutions and investors (Johnson et al., 2017, Käyhkö et al., 2018b). Innovation ecosystem and close interaction and cooperation between different knowledge domains are important enablers in the creation of collaborative atmosphere, where open data and tools turn into locally valuable assets and solutions. Governments' and universities' skills development and employment strategies, STI policies and teaching practices are crucial elements supporting education transformation to innovative, directions meeting various societal needs. In case these assumptions are realized and risks minimized, universities skilled geospatial and ICT graduates, who have witnessed several successful problem-solving learning cases in 
Tanzania, will hopefully be well positioned in the society to catalyse the growth further and open new opportunities for the students, who follow their steps in the future.

\section{ACKNOWLEDGEMENTS}

We are grateful for the financial support for the project from the Ministry for Foreign Affairs of Finland via the HEI-ICI programme. The Higher Education Institutions Institutional Cooperation Instrument (HEI-ICI) supports cooperation projects between higher education institutions in Finland and the developing world. The projects support the HEIs as they develop their subject-specific, methodological, educational and administrative capacity. The programme is funded by the Ministry for Foreign Affairs of Finland and administered by the Finnish National Agency for Education. We would like to thank our home institutions of their financial and collegial support, and all the GeoICT4e and Resilience Academy team members and innovation ecosystem partners for their enthusiasm and cooperation in the project.

\section{REFERENCES}

Avle, S., Quartey, E., Hutchful, D. 2018: Research on Mobile Phone Data in the Global South: Opportunities and Challenges. The Oxford Handbook of Networked Communication. 84. doi.org/10.1093/oxfordhb/9780190460518.013.33.

Bakker, K., Ritts, M. 2018: Smart Earth: A meta-review and implications for environmental governance. Global Environmental Change 52, 201-211. doi.org/10.1016/j.gloenvcha.2018.07.011.

Blevis, E. 2010: Design Challenge Based Learning (DCBL) and Sustainable Pedagogical Practice. Interactions 17, 64-69. doi.org/10.1145/1744161.1744176.

Fritz, S., See, L., Carlson, T., Haklay, M., Oliver, J.L., Dilek F., Mondardini, R., Brocklehurst, M., Shanley, L.A., Schade, S., Wehn, U., Abrate, T., Anstee, J., Arnold, S., Billot, M., Campbell, J., Espey, J., Gold, M., Hager, G., He, S., Hepburn, L., Hsu, A., Long, D., Masó, J., McCallum, I., Muniafu, M, Moorthy, I., Obersteiner, M., Parker, A.J., Weisspflug, M., West S. 2019: Citizen science and the United Nations Sustainable Development Goals. Nature Sustainability 2, 922 930. doi.org/10.1038/s41893-019-0390-3.

Gaskins, W.B., Johnson, J., Maltbie, C., Kukreti, A. 2015: Changing the Learning Environment in the College of Engineering and Applied Science Using Challenge Based Learning. International Journal of Engineering Pedagogy 5(1). http://dx.doi.org/10.3991/ijep.v5i1.4138.

GeoBuiz 2019: Geospatial Industry Outlook \& Readiness Index. https://issuu.com/geospatialworld/docs/20190329geobuiz-report-2019-freeve.

Goodchild, M., Glennon, A. 2010: Crowdsourcing geographic information for disaster response: a research frontier. International Journal of Digital Earth 3, 231-241.
Johnson, P.A., Sieber, R., Scassa, T., Stephens, M., Robinson, P. 2017: The Cost(s) of Geospatial Open Data. Transactions in GIS 21, 434-445. doi.org/10.1111/tgis.12283.

Käyhkö, N., William, C., Mayunga, J., Makame, M., Mauya, E., Järvi, A. 2018a: Building geospatial competences in Tanzanian universities with open source solutions. International Archives of the Photogrammetry, Remote Sensing and Spatial Information Sciences - ISPRS Archives, XLII4/W8, doi.org/10.5194/isprs-archives-XLII-4-W8-93-2018.

Käyhkö, N., Makandi, H., Msilanga, M. 2018b: Geospatial expertise, cooperation networks and development potential in Tanzania. https://agile-online.org/conference_paper/cds/ agile_2018/shortpapers/153\%20AGILE_2018_NKayhko_revis ed_April10th.pdf.

Leinonen, U., Koskinen, J., Makandi, H., Mauya, E., Käyhkö, N. 2018: Open Foris and Google Earth Engine linking expert participation with natural resource mapping and remote sensing training in Tanzania. International Archives of the Photogrammetry, Remote Sensing and Spatial Information Sciences - ISPRS Archives, XLII-4/W8. doi.org/10.5194/isprsarchives-XLII-4-W8-117-2018, 2018.

Madhavan, R. 2018: Robotics and automation for societal good. Global South challenges and technology-policy considerations. Mètode Science Studies Journal 2018, 153-161. doi.org/10.7203/metode.9.12222.

Malmqvist, J., Kohn Rådberg, K., Lundqvist, U. 2015: Comparative Analysis of Challenge-based Learning Experiences. Chengdu University of Information Technology, 11th International CDIO Conference, China. June 8-11, 2015.

Martin, F., Bolliger, D.U. 2018: Engagement matters: Student perceptions on the importance of engagement strategies in the online learning environment. Online Learning, 22, 205-222. dx.doi.org/10.24059/olj.v22i1.1092.

O'Sullivan, C., Wise, N., Mathieu, P.P. 2018: The Changing Landscape of Geospatial Information Markets. In: Mathieu, P.P., Aubrecht, C. (eds), Earth Observation Open Science and Innovation. ISSI Scientific Report Series, vol 15. Springer, Cham. doi.org/10.1007/978-3-319-65633-5_1.

Petersson, L., ten Veldhuis, M-C., Verhoeven, G., Kapelan, Z., Maholi, I., Winsemius, H. 2020: Community Mapping Supports Comprehensive Urban Flood Modeling for Flood Risk Management in a Data-Scarce Environment. Frontiers in Earth Science 8, 304. doi.org/10.3389/feart.2020.00304.

Portuguez Castro, M., Gómez Zermeño, M.G. 2020: Challenge Based Learning: Innovative Pedagogy for Sustainability through e-Learning in Higher Education. Sustainability 12, 4063. doi.org/10.3390/su12104063.

Rådberg, K.K., Lundqvist, U., Malmqvist, J., Svensson, H.O. 2020: From CDIO to challenge-based learning experiences expanding student learning as well as societal impact?

European Journal of Engineering Education 45, 22-37. doi.org/10.1080/03043797.2018.1441265. 
Tiwari, A., Dixit, A. 2015: Unmanned Aerial Vehicle and Geospatial Technology Pushing the Limits of Development. American Journal of Engineering Research (AJER) 4, 16-21.

UNCTAD (United Nations Conference on Trade and Development), 2021: Technology and Innovation Report 2021. Catching technological waves: Innovation with equity. https://unctad.org/system/files/official-

document/tir2020_en.pdf (Accessed on June 15th, 2021).

Young, J.C., Lynch, R., Boakye-Achampong, S., Jowaisas, C., Sam, J., Norlander, B. 2020: Volunteer geographic information in the Global South: barriers to local implementation of mapping projects across Africa. GeoJournal doi.org/10.1007/s10708-020-10184-6. 